\title{
Service evaluation of a UK primary care-based allergy clinic: quality improvement report
}

\author{
*Mark L Levya , Samantha Walker, Angie Woodsc, Aziz Sheikh ${ }^{\mathrm{d}}$ \\ ${ }^{a}$ Clinical Research Fellow, Allergy \& Respiratory Research Group, Division of Community Health Sciences: GP Section, University of Edinburgh, \\ Scotland UK \\ ${ }^{\mathrm{b}}$ Director of Education \& Research, Education for Health, Warwick, UK \\ Service Improvement Manager, Harrow Primary Care Trust, Harrow, London, UK \\ d Professor of Primary Care Research \& Development, Allergy \& Respiratory Research Group, Division of Community Health Sciences: GP \\ Section, University of Edinburgh.
}

Received 17th February 2009; revised version received 23rd April 2009; accepted 5th May 2009; online 8th July 2009

\begin{abstract}
Introduction: Allergic diseases are common, increasing, and associated with significant morbidity and occasional, but potentially avoidable, mortality. There is widespread public, professional and government agreement about the poor quality of care received by many patients with allergic diseases in the UK. Many remain undiagnosed, few have access to specialist services, and the majority of primary care health professionals have no allergy training. We report an evaluation of a novel, UK NHS-funded primary care-based allergy service in North West London.

Methods: The clinic was run by a specialist allergy nurse and a general practitioner (GP) with a special interest in respiratory disease and allergy. Referrals from local GPs were made on dedicated proformas and handled according to developed and agreed community care pathways.

Results: 141/151 (93\%) of those referred attended the clinic. On average, patients waited 15.7 (SD 15.67) days from referral to an offer of an appointment and were seen 18.11 (SD18.07) days from the date of referral. The majority of patients were referred for hives or wheals $(61 ; 40 \%)$, suspected food allergy $(28 ; 40 \%)$, multiple reasons, $(19 ; 12 \%)$ or rhinitis $(19 ; 12 \%)$. Skin prick and specific-lgE tests were performed on $69(49 \%)$ and 19 (14\%) patients respectively, with $4(0.3 \%)$ patients having both. We estimated an overall saving of at least $\mathrm{f} 13,580$ to the local health economy - through reduced secondary care referrals - during the nine months' duration of the clinic. Assessed using a validated patient satisfaction questionnaire, most patients rated their satisfaction with the service with an overall median score of 75\% (IQR 65.64-82.32).

Conclusions: A primary care allergy service provided by appropriately trained personnel can cater adequately for the majority of primary care referrals. This model provides a pathway of care that supports self-directed care, reduces inappropriate referrals, and encourages care in the local community. The model is one that could easily be developed further into a clinical assessment service for allergy including respiratory based (asthma) problems. This would expand the scope and ensure value for money as well as responding to a clinical need with significant incidence locally. The UK Department of Health should consider rolling out this primary care-based model nationally.

(C) 2009 General Practice Airways Group. All rights reserved.

ML Levy et al. Prim Care Resp J 2009; 18(4): 313-319

doi:10.4104/pcrj.2009.00042
\end{abstract}

Keywords allergy, management, anaphylaxis, rhinitis, primary care, observational

The full version of this paper, with online Appendices,

is available online at www.thepcrj.org

\section{Introduction}

Allergic disorders are common, increasing in prevalence and account for a significant proportion of general practice consultations. ' While most are intermittent and mild to moderate in severity (rhinitis, asthma and eczema) some (such as food, venom and drug allergy) are persistent and lifethreatening. All are associated with some level of morbidity,

\footnotetext{
* Corresponding author: Dr Mark L Levy, Allergy \& Respiratory Research Group, Division of Community Health Sciences: GP Section, University of Edinburgh, Edinburgh, EH8 9DX, Scotland, UK. E-mail: Mark.Levy@ed.ac.uk
} 
and some have been associated with a detrimental impact on daily activities including disruption of concentration and learning ability. ${ }^{2}$ The Royal College of Physicians, UK Department of Health (DH), and House of Lords Science and Technology Committee, have recently expressed concerns about poor service provision for patients with allergic disorders. ${ }^{3-5}$ A recent editorial in the Lancet highlighted a report detailing the annual health care costs of allergic rhinitis in the USA in 2005 - in excess of $\$ 11$ billion. ${ }^{6}$ The main problems centre on lack of availability of diagnostic testing, poor access to specialist services, and the failure to attend adequately to the long-term needs of those with potentially life-threatening allergic problems. The lack of training opportunities for non-specialists - be they in primary or secondary care - further compounds this problem.

A number of models for improving delivery of allergy services have been proposed. These include enhancement of the traditional primary care model by increasing the skills of community-based health professionals with referral to tertiary and secondary specialist allergy clinics as appropriate, and intermediate approaches such as the development of regional primary care-based practitioners with specialist interests in allergy, the latter being supported by increased numbers of hospital-based allergists. ${ }^{7-9}$ The Lancet editorial ${ }^{6}$ related the findings of the USA survey to the lack of provision of services for allergy patients in the UK, and concluded by suggesting a possible role for community pharmacists in managing these patients. In this evaluation report, we propose another model.

The concept of practitioners with specialist interests was first introduced in the UK through the National Health Service (NHS) Plan in 2000, ${ }^{10-12}$ but only in certain specific disease areas. Various UK primary care organisations have employed general practitioners (GPs) and other Practitioners with Special interests (GPwSIs/PwSIs), but to our knowledge our primary care-based locally enhanced allergy service in Harrow, London is the first ever primary care-based allergy initiative of its kind. Funding was made available by the Harrow Primary Care Trust (PCT) through a local enhanced scheme (LES), for a six-month pilot service, which was then extended for a further three months before being closed down (apparently because of competing financial priorities and constraints). The decision to cease the pilot was taken as part of the PCT programme to develop LESs in a variety of ways and in competition with other initiatives; for example, the obesity LES was at that stage put on hold but is now currently being piloted again. The measurable outcomes at the time were dictated by the $\mathrm{DH}$ and it was therefore difficult to demonstrate directly a reduction in waiting times and a reduction in referrals specifically for this pilot.

A key aim from the PCT perspective - in view of their severe financial constraints at the time - was to manage (i.e. reduce) referrals from primary to secondary care. In view of the real shortage of evidence to support service development in this area, we decided to report on the establishment, development and evaluation of our pilot allergy clinic, in the hope that other forward-thinking PCTs and possibly also the DH can consider setting up other similar services.

\section{Methods}

\section{The allergy service}

Harrow PCT is a busy, multi-ethnic organisation based in Kenton, North West London, responsible for providing primary and secondary care services for about 250,000 people. Funding of $£ 22,500$ ( $£ 2,500$ per month, including staff, premises, equipment and laboratory costs) was made available initially for six months; this was then extended for a further three months before being withdrawn. At the time, there were no local allergy clinic services available; however, three of the small number of allergy clinics with a full time allergist in the $\mathrm{UK}^{13}$ were accessible, within about an hour's travelling time in London.

\section{Setting up and running the allergy service}

The discussions and negotiation with the PCT and local GPs leading to the establishment of the clinic took place over a two-year period, culminating in the production of an agreed service delivery plan which included a detailed overview of the pathways of care and standards that we aimed to achieve (see online Appendix 1 at www.thepcrj.org for further details). The plan included details of eligible patients for referral to the clinic, this having been agreed after careful consideration of those patients who were felt most appropriate for management by a community-based practitioner with a special interest in allergy. The patient referral and patient care pathway is detailed in Figure 1 and Appendix 1 , the latter detailing the referral criteria and likely pathway when patients attended the clinic.

\section{Aims of the locally enhanced primary care allergy service}

The overall aims of the allergy clinic service were to:

- Improve the care of patients with allergy and improve their symptoms and quality of life

- Provide education and advice to enable patients to manage their own symptoms as far as possible within primary care settings.

- Ensure appropriate pharmacological and nonpharmacological management

- Reduce inappropriate referrals to secondary or tertiary care.

Core activities performed in the community allergy clinic

Referrals from local GPs were made on specific proformas, (see Appendix 1). The core activities of the clinic, which was 


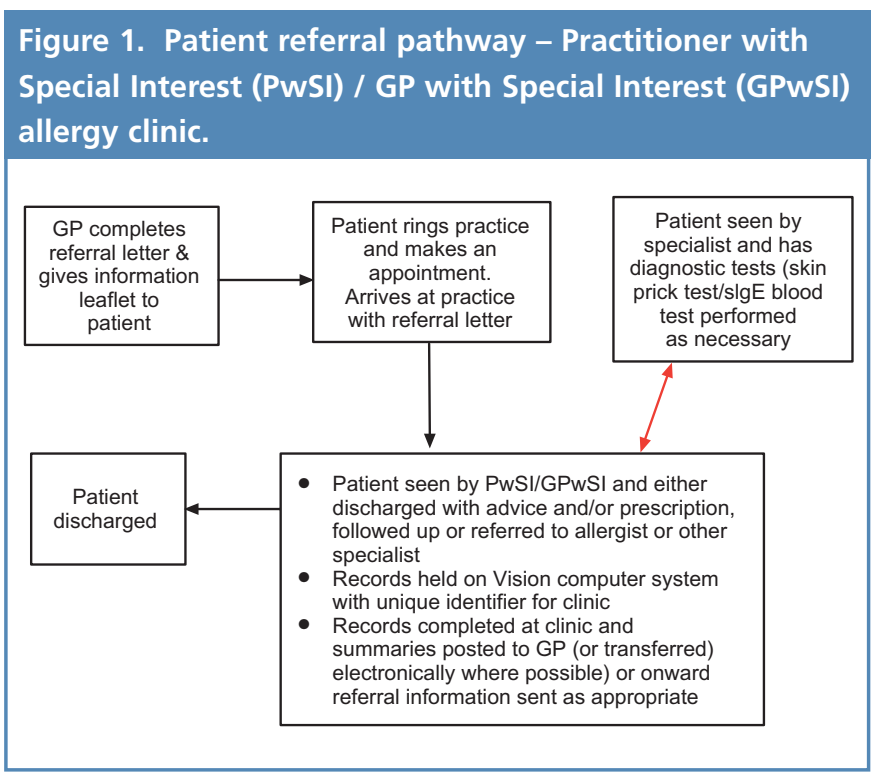

run by a specialist allergy nurse (SW) and a GP with a special interest in respiratory disease and allergy (ML), were to:

- Confirm or refute a diagnosis of allergy previously suspected by the GP or the patient

- Maximise lifestyle by abolishing symptoms through minimum treatment and advise GPs on prescribing

- Facilitate self-management by patients via patient education, allergen avoidance advice and correct use of medication

- Encourage appropriate follow-up of patients

- Identify those patients who required onward referral to secondary and tertiary care specialists

- Further develop and facilitate implementation of a comprehensive care pathway for community-based patients experiencing problems with a possible allergic basis.

\section{Clinical support, education and liaison}

SW and ML had developed a network of allergy experts to whom they could refer patients or with whom they could discuss any clinical problems. Both practitioners were considered suitably qualified by the PCT to provide the service, given their combined experience in respiratory disease and allergy management.

\section{Equipment and investigations}

The presence or absence of an IgE-mediated trigger for symptoms such as rhinitis, urticaria and food and drug reactions was investigated as necessary by taking a detailed history supported by skin prick tests to common aeroallergens (house dust mite, mixed grass pollen, cat, dog and tree pollens) where indicated (supplied by Allergy Therapeutics Ltd, Worthing UK and ALK-Abello UK, Hungerford, Reading UK). Specific IgE (slgE) blood tests for penicillin, insect venom and foods (where skin prick tests are not considered safe to be performed in primary care) were not available through the local NHS hospital trust and were therefore organised through a private laboratory (The Doctors Laboratory, London); we did, however, make use of the local NHS phlebotomy service (see Appendix 1). Blood test results were faxed back to the clinic within a few days of patients being seen and patients were asked to return to the clinic to discuss the results.

Prescriptions for patients referred to the allergy clinic from outside the host practice were not normally provided by the allergy clinic, so appropriate prescribing advice was provided for the referring GP. Where emergency medication was needed - as in the case of one patient needing a supply of self-injected adrenaline - the clinician contacted the referring practice in order to expedite the issue of an urgent prescription.

\section{Key measures of improvement}

Reduction in cost of referrals to hospital-based specialist care From the PCT's perspective, the main outcome of interest was a reduction in referrals to hospital-based specialist care. However, there was no accurate way of measuring this because there was no system for GPs to record referrals for possible allergic conditions; local hospital discharge data, which would in any case only provide an incomplete picture, were not available in a useable format for this purpose. Therefore, referring practitioners were asked to document, on the referral proforma, whether they would otherwise (if the clinic did not exist) have referred the patient elsewhere. On the basis of these data and the final outcome following the assessment in the allergy clinic (i.e. onward referral or not), estimates of hospital outpatient activity were used to perform an economic analysis on the potential cost implications of running our clinic. For this analysis, we estimated the costs of initial (first time) outpatient charges. From the PCT's "hospital activity validation exercise" at the time of the clinic, for which the Harrow practices checked their records against the local hospital charges for services, North West London Hospitals (NWLH) charged anywhere between $\mathrm{f160-f240} \mathrm{(178-268}$ Euro; 233-349 US Dollars) per initial visit (the latter for paediatrics). Current costs of outpatient clinic attendances at the local hospital were compared with the actual cost of running the clinic in primary care.

\section{Patient satisfaction questionnaire}

We were also interested in outcomes important to patients. A self-completion patient satisfaction questionnaire was given to all attending patients. We used the validated Consultation Satisfaction Questionnaire (CSQ) ${ }^{14,15}$ (see Appendix 3 online at www.thepcrj.org). The CSQ asks patients for their opinions of the consultation. The questions concern four components of care: general satisfaction with the consultation; opinions on the professional aspects of the consultation; the depth of the relationship; and the perceived duration of the consultation. 
Patients scored the 18 questions from 1 (strongly agree) to 5 (strongly disagree) and the scores were analysed, to include converting them to a 0-100 scale according to the manual provided by its designer ( $\mathrm{R}$ Baker, personal communication, 2006) with whom the copyright rests.

\section{Results}

\section{Take-up of the service}

151 patients (34 of whom were children under 16 years old) were referred by local GPs during the nine-month clinic intervention period. The reasons for referral are detailed in Table 1, with most due to suspected allergic skin rashes and food allergy. A number of referrals (10 patients, 7\%) were not accompanied by the proper referral forms, or the reason was not one of the six on our referral criteria (these were therefore coded as 'other'). 141 (92\%) of those referred attended for their appointment, 139 attending after the initial appointment letter and two attending after receiving a single reminder letter.

\section{Impact on hospital referrals}

The GPs stated that they would have referred 99 (66\%) of the patients to secondary or tertiary care had the allergy clinic not been available. The named specialities were to a tertiary allergy clinic (47\%), a dermatologist (29\%) and the remainder to general physicians, ear nose and throat specialists, gastroenterologists and general paediatricians.

\section{Access times}

On average, patients were seen 18.72 (SD18.07) days from the date of referral. Some of these patients were referred before the clinic started and therefore the access times (from referral to date appointment was offered) have been underestimated for these patients; we have assumed these patients were referred when the clinic started.

\section{Allergy tests and referrals}

Skin prick and specific-lgE tests were performed on 69 (48.9\%) and 19 (13.5\%) patients respectively, with four patients having both. Blood test results were faxed back to the clinic within a few days. Following assessment, $13(9 \%)$ of patients were recommended for onward referral to tertiary allergy specialists by the two clinicians running the clinic.

\section{Economic evaluation}

From June 2005 to March 2006, 141 patients were seen in clinic costing an estimated $\mathrm{f} 159.57$ per patient based on the total budget cost for the clinic. Had the service been fully utilised (i.e. all available appointments (193) fully booked), this would work out at just under $£ 116.58$ per patient visit.

Given that GPs stated in their referrals that they would have referred at least 99 of these patients, and considering that after assessment in the allergy clinic 13/141 patients were recommended for onward referral, the clinic saved at least 86 secondary care referrals (including 14 patients under 16 years

Table 1. Doctors stated reasons for referral to the
Harrow Allergy Clinic.
\begin{tabular}{ll} 
Reason for referral & Numbers (\%) \\
\hline Hives or Wheals & $61(40)$ \\
\hline Food allergy & $28(19)$ \\
\hline Multiple reasons & $19(12)$ \\
\hline Rhinitis & $19(12)$ \\
\hline Other reasons & $10(7)$ \\
\hline Not stated & $5(3)$ \\
\hline Anaphylaxis & $4(3)$ \\
\hline Penicillin allergy & $4(3)$ \\
\hline Venom allergy (bee or wasp) & $1(1)$ \\
\hline Total & $151(100)$
\end{tabular}

of age). At current hospital charges with a minimum cost of $f 160$ (adult) and $£ 240$ (paediatrics) per patient (178-268 Euro; 233-349 US Dollars) this therefore represents a net saving of at least $f 14,880$ (16634 Euros; 21687 US Dollars) over the ninemonth period.

Additionally, 20 patients (13\%) had multiple reasons for referral. We have assumed for the purpose of this paper that at least two additional referrals to organ-based specialists would have been made for each of these 20 patients. This equates to additional savings of at least $£ 6,400$ (i.e. $40 \times f 160$ at the lowest cost). We therefore estimate that the clinic saved an estimated minimum of $f 21,280(f 14,880+f 6,400)(23776$ Euros; 31008 US Dollars, through reducing referrals to secondary and tertiary care. We have not included an estimate of follow-up appointments in this analysis; their inclusion would certainly increase the costs, and therefore the potential savings.

\section{Patient satisfaction questionnaires}

Only 71 (49.6\%) CSQs were completed by patients. The results are shown in Table 2 and clearly reveal high levels of satisfaction amongst respondents.

\section{Discussion}

The need for improved primary care provision for patients with allergy was clearly shown in a survey of 500 general practitioners in the UK: $i^{16}$ there was evidence of lack of allergy training, long delays for patients to access specialist services and, as a result, a significant proportion of patients being managed for complex allergies by untrained GPs. In this service evaluation, the introduction of a community-based locally-enhanced allergy service appeared to offer substantial cost savings in terms of referral to secondary or tertiary care, and this was associated with a high degree of patient satisfaction. 


\begin{tabular}{|c|c|c|c|c|c|}
\hline & General Satisfaction & Professional Care & Depth of Relationship & Percieved Time & Total score \\
\hline Median & 75 & 75 & 65 & 75 & 74.94 \\
\hline (Quartile 1, Quartile 3) & $(66.67,91.67)$ & $(71.43,89.29)$ & $(58.46,75.00)$ & $(66.67,91.67)$ & $(65.64,82.32)$ \\
\hline
\end{tabular}

Strengths of our approach include the fact that this was a real-life and real-time evaluation of a potentially routine service, and the fact that the process has provided a wealth of information about the planning and implementation of such a service that can be replicated by others. Limitations include the relatively imprecise method of attributing costs to different components of the service and the proxy method of estimating the need for, and cost of, onward referral. This is of particular relevance to costing allergy service utilisation in the secondary care hospital setting, where patients with undiagnosed allergic conditions might flow through a number of organ-based disciplines before an allergy diagnosis is made; this was highlighted by the lack of available data during the Houses of Commons and Lords Enquiries respectively. ${ }^{3-5}$ There is also the risk of bias in this uncontrolled evaluation. Nevertheless, we think that this evaluation provides a unique and important contribution to the debate on the issues of providing locally enhanced services.

Although UK government policy currently devolves decisions for implementation of health care to local funding bodies such as PCTs, these bodies are largely driven by targets set by central government - as are many GPs. Much local focus is therefore directed to those providing nationally(government-) prioritised services, supported by National Service Frameworks (e.g. cardiovascular disease and diabetes). Developments in other areas such as allergy and rheumatology have been neglected, ${ }^{6}$ and this is unlikely to change in the near future. Given the recent recommendations by the $\mathrm{DH}$ and the House of Lords that allergy should largely be managed in primary care, ${ }^{3-5}$ and latterly the development of a National Occupational Standard for Allergy, ${ }^{17}$ the findings from our service evaluation provide suggestive evidence that local healthcare organisations can provide a cost-effective allergy service in primary care.

The aforementioned survey of 500 GPs $^{16}$ identified that many patients with allergy are treated by GPs without any basic training in allergy. While many international allergy guidelines are written by secondary care specialists, some have been written by, ${ }^{17}$ and have had input from, ${ }^{18}$ primary care specialists. However, whilst these guidelines are available to GPs, there is no evidence of their widespread implementation. While there is a clear need to improve training at undergraduate and postgraduate levels for primary care providers, there is also a case (as we have demonstrated) for provision of care by more specialised primary care health providers. There are training and organisational implications inherent in establishing specialist primary care allergy services, although help in the form of National Occupational Standards ${ }^{19}$ (developed by Skills for Health in conjunction with the UK DH) will provide a useful basis for curriculum development. Clearly it is important that any primary care health professional providing specialist services has appropriate training and experience, but it can be seen from the characteristics of the patients referred to the clinic that the majority can be managed in primary care without further referral. Structured allergy training has been shown to improve health outcomes in a primary care patient population whilst improving the confidence and competence in health professionals in managing allergic diseases. ${ }^{20}$

- In this clinic, two appropriately trained clinicians were able to see and treat satisfactorily the majority of patients in their local environment, while at the same time also delivering substantial cost savings for the NHS. One of the major problems for the clinic organisers and therefore for the PCT was that it was not possible to determine which patients were being referred to hospital for allergic problems from the referral and hospital consultation data. There are multiple reasons for this, mainly the fact that many patients suffering from undiagnosed allergic disease are referred to organ-based specialists - sometimes repeatedly to different clinicians before an allergy diagnosis is made. The reasons for referral are obvious in the case of those referrals being made to dedicated allergy clinics; however, these data are not readily available to the PCT in real-time, and this is further complicated by the fact that there are less than 10 tertiary allergy clinics staffed by a full time allergist in the UK. ${ }^{13}$ While the majority of patients were referred for dermatological symptoms (42\%) and possible food allergy (19\%), 13\% of these patients were referred for 'multiple allergic problems' (such as co-existent rhinitis, urticaria, asthma and anaphylaxis) and it is likely that these patients would have been referred to more than one outpatient clinic for investigation and management of their problems. We therefore had to rely on the information provided by referring GPs in order to derive our main outcome measure - namely an estimation of reduction in secondary care referrals. We achieved this by using agreed clear proformas (as discussed above). For those initiating a similar pilot in the UK, the Secondary Uses Survey 
(SUS) data, may be helpful. ${ }^{21}$ These data are derived from information required of service providers by those who commissioned the care. The SUS Service is the single repository of person- and care event-level data relating to the $\mathrm{NHS}$ care of patients. This is used for management and clinical purposes other than direct patient care, including healthcare planning, commissioning, clinical audit, benchmarking, research and clinical governance.

The fact that the PCT limited referrals to this clinic by excluding patients with problematic asthma probably reduced the number of referrals and therefore, by extrapolation, further savings. In addition, the premature termination of the service after nine months - apparently because of competing financial priorities and constraints - may further have reduced its impact and cost-effectiveness; it took approximately three months for local GPs to become fully aware of, and to appreciate, the possible role of the primary care-based allergy clinic. This initial lack of clinic utilisation also somewhat artificially inflated the cost per attendance and needs to be taken into account in relation to longer-term economic modelling.

\section{Conclusion}

With at least one-third of the UK population suffering from an allergic problem at some stage of their lives, widespread concern about the poor quality of primary care for many of these patients, and ongoing problems with lack of access to specialist care, there is clearly a need to improve allergy services. We have demonstrated that it is feasible to deliver a primary care-based specialist service for people with allergy, with beneficial patient-focussed and economic outcomes.

In England and Wales, a new method for commissioning care is being utilised - practice-based commissioning. As this develops, GPs will become more aware of the need to prevent multiple referrals of those with allergy to secondary and tertiary care. Our model provides a pathway of care that supports self-directed care, reduces inappropriate referrals, and encourages care in the local community. The model is one that could easily be developed further into a clinical assessment service for allergy, including respiratory-based (asthma) problems. This would expand the scope of the clinic and ensure value for money as well as responding to a clinical need with significant incidence locally.

\section{Authors' contributions}

MLL participated in the development of the service specification, launch and running of the PWS/GPWSI Allergy Clinic, analysed the results, and was the lead author of the final paper. He had full access to all the data in this report, was responsible for the decision to submit for publication, and has seen and approved the final version of the paper.

SW participated in the development of the service specification, launch and running of the PWSI/GPWSI Allergy Clinic, and contributed to the final paper. She has seen and approved the final version of the paper.
AW participated in the development of the service specification, launch and monitoring of the PWSI/GPWSI Allergy Clinic, contributed to the final paper, and has seen and approved the final version of the paper.

AS participated in the development of the service specification, advised on the plans for evaluating the PWSI/GPWSI Allergy Clinic, contributed to the final paper, has seen and approved the final version of the paper

\section{Conflict of interest declarations}

MLL has accepted sponsorship from GlaxoSmithKline, AstraZeneca, Trinity-Cheisi, Merck Sharpe and Dohme, Merck, Altana Pharma, Novartis, Meda Pharmaceuticals, $3 \mathrm{M}$ Pharmaceuticals, Schering Plough for attending conferences. He has accepted lecture fees from Boehringer Ingelheim, GlaxoSmithKline, AstraZeneca and AlkAbello. He has been on advisory boards or provided consultancy for Schering Plough, Merck Sharp and Dohme, Trinity- Cheisi, Altana Pharma, Ranbaxy, AstraZeneca, 3M Pharmaceuticals and Novartis. In addition, he has received research grants from GSK, Schering Plough, Boehringer Ingelheim, Pfizer, and Astra Zeneca. He has also received an educational grant from Lincoln Medical Ltd for development of an online audit for health professionals on injectable adrenaline. He is a member of ADMIT (The Aerosol Drug Management Improvement Team) which is funded by an educational grant from MEDA Pharmaceuticals.

SW has received research monies and honoraria for writing, consultancy and lecturing from Schering Plough UK and Astra Zeneca UK. She has also received honoraria from UCB Pharma, GlaxoSmithKline, Pfizer and MSD for lectures and consultancy.

AW has no conflicts of interest to declare.

AS has advised the Department of Health and Scottish Government Allergy reviews and gave evidence to the House of Lords Allergy Inquiry.

Mark Levy is the Editor-in-Chief, Aziz Sheikh is an Assistant Editor and Samantha Walker is an International Editorial Advisory Board Member of, the PCRJ. None of them were involved in the editorial review of, nor the decision to publish, this article.

\section{Funding declaration}

The Harrow Primary Care Trust funded this service. They were involved in the initial design, implementation and monitoring of the service. AW was the key link person working for the PCT. $\mathrm{f} 22500$ was paid for provision of premises, salaries for MLL and SW, equipment, blood tests and administrative costs associated with providing the service.

Additional funding was provided by Schering Plough Ltd, who funded the initial launch meeting at a local hotel where ML, SW and AW presented the outline of the service and advised local practitioners how to access the service.

\section{References}

1. Royal College of Physicians. Allergy: the unmet need. London: Royal College of Physicians of London; 2003. Report No.: ISBN 1860161839.

2. Walker S, Khan-Wasti S, Fletcher M, Cullinan P, Harris J, Sheikh A. Seasona allergic rhinitis is associated with a detrimental effect on examination performance in United Kingdom teenagers: Case-control study. J Allergy \& Clin Immun 2007;120(2):381-7. http://dx.doi.org/10.1016/j.jaci.2007.03.034

3. Sixth Report of session 2003-04, Presented to parliament by the Secretary for State for Health by Command of her majesty January 2005. Government response to the House of Commons Health Committee Report on the provision of allergy services. The Stationery Office; 2005. Report No.: Cm 633; ISBN 010 1643322

4. Select Committee on Health Sixth Report. House of Commons Health Committee. The provision of allergy services. HC 696_I 2004. London: The Stationery Office. Available from: URL: http://www.publications.parliament.uk/ pa/cm200304/cmselect/cmhealth/696/69604.htm\#a3

5. House of Lords. Science and Technology - Sixth Report. 2007Available from: URL: http://www.publications.parliament.uk/pa/ld200607/ldselect/ldsctech/ 166/16602.htm

6. Anonymous, Anon. Allergic rhinitis: common, costly, and neglected. Lancet 2008;371[9630]:2057. http://dx.doi.org/10.1016/S0140-6736(08)60891-0

7. Ryan D, Levy M, Morris A, Sheikh A, Walker S. Management of allergic problems in primary care: Time for a rethink? Prim Care Resp J 2005;14(4):195203. http://dx.doi.org/10.1016/j.pcrj.2005.01.003 
8. Williams S, Ryan D, Price D, Langley C, Fletcher M, Everden P. General practitioners with a special clinical interest: A model for improving respiratory disease management. Br J of Gen Pract 2002;52(483):838-43.

9. Levy ML, Sheikh A, Walker S, Woods A. Should UK allergy services focus on primary care? BMJ 2006;332(7554):1347-8. http://dx.doi.org/10.1136/ bmj.332.7554.1347

10. Department of Health. General Practitioners with Special Interests. 2000Available from: URL: http://www.dh.gov.uk/PublicationsAndStatistics/ Publications/PublicationsPolicyAndGuidance/PublicationsPolicyAndGuidanceArt icle/fs/en?CONTENT_ID=4009510\&chk=VuRE9U (Accessed 21/6/2008)

11. Department of Health. Guidelines for the appointment of general practitioners with special interests in the delivery of clinical services: respiratory medicine. 2003 April 4 [cited 2005 Sep 30];Available from: URL: http://www.dh.gov.uk/PublicationsAndStatistics/Publications/PublicationsPolicy AndGuidance/PublicationsPolicyAndGuidanceArticle/fs/en?CONTENT_ID=4009 510\&chk=VuRE9U (Accessed 21/6/2008) (Accessed 21/6/2008)

12. Department of Health. The NHS Plan. 2005 [cited 2005 Jan 21];Available from: URL: $\quad$ http://www.dh.gov.uk/PublicationsAndStatistics/Publications/ AnnualReports/DHAnnualReportsArticle/fs/en?CONTENT_ID=4064827\&chk=3 ReuSO (Accessed 21/6/2008)

13. BSACI. British Society for Allergy and Clinical Immunology. 2008 [cited 2008 Jun 26];Available from: URL: http://www.bsaci.org/clinics/UK

14. Baker R. The reliability and criterion validity of a measure of patients' satisfaction with their general practice. Fam Pract 1991;8(2):171-7. http://dx.doi.org/10.1093/fampra/8.2.171

15. Baker R. Development of a questionnaire to assess patients' satisfaction with consultations in general practice. Br J of Gen Pract 1990;40(341):487-90.

16. Levy ML, Price D, Zheng $X$, Simpson $C$, Hannaford $P$, Sheikh A. Inadequacies in UK primary care allergy services: National survey of current provisions and perceptions of need. Clinical and Experimental Allergy 2004;34(4):518-19. http://dx.doi.org/10.1111/j.1365-2222.2004.1945.x

17. Price D, Bond C, Bouchard J, et al. International Primary Care Respiratory Group (IPCRG) Guidelines: Management of allergic rhinitis. Prim Care Resp J 2006;15(1):58-70. http://dx.doi.org/10.1016/j.pcrj.2005.11.002

18. Allergic Rhinitis and its Impact on Asthma (ARIA) 2008 update (in collaboration with the World Health Organization, GA(2)LEN and AllerGen). Bousquet J, Khaltaev N, Cruz AA, et al. Allergy 2008;63 Suppl 86:8-160.

19. Sector Skills Council (SSC) for the UK health sector. Skills For Health. 2008 [cited 2008 May 2]; Available from: URL: http://www.skillsforhealth.org.uk/ (Accessed 21/6/2008)

20. Sheikh A, Khan-Wasti S, Price D, Smeeth L, Fletcher M, Walker S. Standardized training for healthcare professionals and its impact on patients with perennial rhinitis: a multi-centre randomized controlled trial. Clin Exp Allergy 2007;37(1):90-9. http://dx.doi.org/10.1111/j.1365-2222.2006.02619.x

21. Secondary Uses Service (SUS). Connecting for Health, United Kingdom Department of Health. http://www.connectingforhealth.nhs.uk/ systemsandservices/sus/?searchterm=secondary+care+users (accessed 5/7/2008).

\section{Available online at http://www.thepcrj.org}




\section{Appendix 1 PwSI(GPwSI) Allergy Clinic service specification, Harrow, 2005}

\subsection{Overall aim of the PwSI allergy service}

1.1 To improve the care of patients with allergy and improve their symptoms and quality of life

1.2 To reduce inappropriate referrals to secondary or tertiary care

1.3 To ensure appropriate pharmacological and nonpharmacological management

1.4 To provide education and advice to enable patients to manage their own symptoms as far as possible

\subsection{Objectives:}

2.1 To confirm or refute a diagnosis of allergy previously suspected by the GP or the patient

2.2 To further develop and implement a care pathway for patients with allergy

2.3 To maximise lifestyle by abolishing symptoms through minimum treatment - advise GPs on prescribing

2.4 To facilitate self-management by patients via patient education, allergen avoidance advice and correct use of medication

2.5 To ensure appropriate follow-up of patients

2.6 To reduce inappropriate referrals to allergists/immunologists/ENT specialists etc for allergy sufferers, thereby reducing waiting times

\subsection{Core activities for PwSI Allergy}

3.1 Assess, review and advise on management of those with rhinitis; identify allergic trigger if necessary

3.2 Assess, review and advise on management of those with acute urticaria; identify triggers and advise on avoidance

3.3 Assess, review and advise on management of those with chronic urticaria, attempt to identify triggers where appropriate

3.4 Assess, review and advise on management of those with reactions to foods - true food allergy ( 2\%) - diagnose, identify triggers, blood tests for specific lgE (slgE) where appropriate, advise on avoidance and risk of anaphylaxis, prescribe/advise prescription of emergency epinephrine, provide urgent note for GP to prescribe anaphylaxis pack, provide patient with instructions on use and if appropriate, advise on need for referral - food intolerances - ( $98 \%$ of people with suspected food allergy) - diagnose, advise on diet, reassure regarding non-life threatening nature of symptoms

3.5 Assess, review and advise on management of those with suspected drug allergy, testing for those with penicillin allergy and referring to secondary care where appropriate
3.6 Assess, review and advise on management of those with suspected insect venom allergy, including identification of triggers using diagnostic tests where necessary, advising on avoidance and risk of anaphylaxis

3.7 Assess, review and advise on management of those with suspected anaphylaxis including identification of triggers using diagnostic tests where necessary

3.8 Refer on to an allergist/immunologist those: with diagnostic uncertainty needing specialist investigations needing specialist care

3.9 Act as a point of reference for other local GPs with regard to advice, treatment and prescribing

3.10 Encourage local GPs to manage simple allergic problems within the primary care setting and act as a resource for advice and education

3.11 Initiate, facilitate and participate in education sessions for local GPs with regard to allergy

\subsection{Clinical service}

4.1 Link with local A/E staff \& Consultants to develop pathway for those with suspected anaphylaxis resident in Harrow presenting at $\mathrm{A} / \mathrm{E}$

4.2 Link with adult allergist

4.3 Link with paediatric allergist/dermatologist

4.4 Link with Immunologist

4.5 Advise prescription of medication for patients attending PwSI/GPwSI service

\subsection{Education and liaison}

5.1 Maintain up to date knowledge and skills on the management of patients with allergy by attendance at appropriate conferences and workshops, and by maintaining strong existing links with Consultant Allergists/Immunologists

5.2 Provide educational support and information (allergen avoidance, use of Epi-pens, nasal sprays etc) to patients with allergies

5.3 Develop standard documentation for referral to PwSI and templates for annual review and audit of patients with allergies. Develop standard documentation for discharge summaries and onward referral for those who attend the PwSI / GPwSI clinic

5.4 Practice to act as an exemplar/model for local practices

5.5 Provide information and support for practices on treatment/management of allergy

5.6 Hold up to date information on research and evidence base for management of allergy. 
ML Levy et al.

\subsection{Service development/leadership}

6.1 Provide clinical co-leadership for developing allergy services in Harrow PCT

6.2 Co-lead the development of shared care services for those with allergy

6.3 Improve the care provided by GPs for their patients with allergy

\subsection{Core competencies}

7.1 Able to conduct a full allergy history with access to investigations and accurate diagnosis of different allergic diseases

7.2 Able to perform in-house diagnostic tests (skin prick tests) and interpret the results

7.3 Able to order other appropriate allergy blood tests (specific lgE) from local laboratories and interpret the results, including wasp venom, bee venom, peanut, milk, egg, wheat, shellfish and penicillin

7.4 Understand the natural history of allergy

7.5 Understand the multi-system nature of allergic disease

7.6 Has a sound knowledge of pharmacological treatments for allergic diseases, their uses, side effects, drug interactions and contraindications

7.7 Makes appropriate referral to appropriate specialists

7.8 Establishes a register of patients and can audit recall and outcomes

7.9 Has knowledge of patient support mechanisms

7.10 Understands the network support available to patients via other agencies and disciplines.

8.0 Evidence of training and experience/maintenance of competencies

The PCT was satisfied that the combined experience of the PWSI and the GPWSI was appropriate for the purpose of delivering care for this service.

\subsection{Accreditation process}

The PCT were satisfied that the PWSI and GPwSI met their criteria for accreditation for the purpose of this post

\subsection{Types of patients to be referred}

10.1 Patients with rhinitis symptoms of sneezing, nasal blockage, rhinorrhoea etc that are unresponsive to combination of nasal steroids and oral antihistamines

10.2 Patients who present with acute or chronic hives, or allergic-type wheals or history/signs of suspected allergic facial swelling

10.3 Patients with suspected food allergy, particularly those who develop symptoms soon after eating and may have food allergy, but also those with atypical symptoms attributed to food

10.4 Patients with a suspected drug reaction to penicillin that is not considered to be an expected side effect of the drug

10.5 Patients with systemic reactions to a bee, wasp or unknown insect sting

10.6 Patients who have had a suspected anaphylactic episode

11.0 Patients to be referred to an Allergist or appropriate specialist

11.1 Patients who are not responding to treatment

11.2 Patients who require doses or drugs that are unlicensed for a particular condition

11.3 Patients who require skin prick testing with nonaeroallergens which are not available as a specific IgE test (eg fruits, vegetables, drugs)

11.4 Patients who are candidates for specific allergen immunotherapy

11.5 Patients who require food challenges

11.6 Patients with unilateral nasal blockage and bloodstained nasal discharge

11.7 Patients in whom there is diagnostic uncertainty

\subsection{Suggested pathway of care}

See following pages at end

\subsection{Response times}

13.1 Waiting times for PwSI Allergy would be aimed at less than two weeks

13.2 Fast track access to adult and paediatric Allergy Consultant will be developed

\subsection{Referral pathway}

\section{Patient Referral Pathway - PwSI Allergy Clinic}

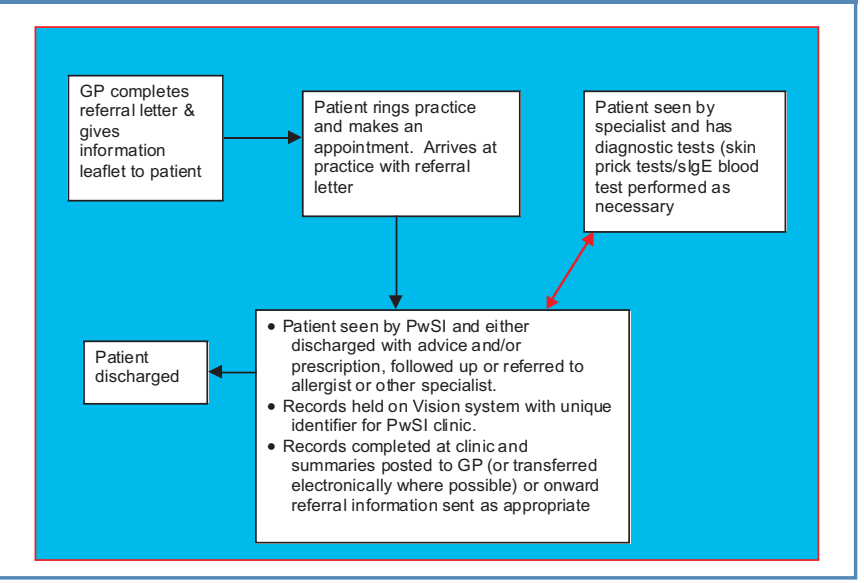




\subsection{Communication pathways}

15.1 Referring doctors will need to complete the referral proforma

15.2 Referring doctors will be notified if patients do not attend

15.3 A letter will be sent to the referrer within 2 weeks after the patient has been seen. If medication is needed, a handwritten/typed note will be given to the patient to take back to the GP.

15.4 If secondary or tertiary referral is needed/deemed necessary by PWSI or GPWSI, the patients GP will be advised. In cases where delay would potentially harm the patient, eg true history of anaphylaxis, PWSI or GPwSI will refer the patient directly to St Mary's Allergy Clinic.

15.5 Results: The Doctors Laboratory will fax results to PWSI or GPwSI to be interpreted and forwarded to GPs with advice on treatment. The aim will be for local facilities for testing to be developed and results sent electronically.

\subsection{Facilities}

16.1 Reception

16.2 Waiting room

16.3 Consultation rooms (X2)

16.4 Skin prick testing equipment

16.5 Resuscitation equipment

16.6 Phlebotomy - during the evaluation phase, will be carried out either at KBMC, or at the local phlebotomy walk-in clinic. The aim will be to develop near patient testing at the time of consultation.

\subsection{Clinical governance}

17.1 PWSI and GPWSI will keep their skills up to date and attend specialist conferences in this field. In particular $\mathrm{BSACl}$ in July 2005 (SW attended the AAAAI conference in the USA in March)

17.2 PWSI or GPWSI will co-consult where necessary

17.3 PWSI or GPWSI will consult specialists for advice where necessary

\subsection{Risk management}

18.1 Clinical accountability rests with the referring GP until the patient details reach PWSI or GPwSI, or the inappropriate referral is returned to the GP
18.2 Where Surgery Reception staff follow the protocol, they will not have any "duty of care" to the patient, this rests with the referring GP

18.3 Where reception staff are unsure with regards to the pathway for the referral, they will bring the details to the attention of PWSI or GPwSI

18.4 Where local GPs are identified as referring inappropriately, GPWSI will liaise with PCT Medical Adviser and the GP tutors, to ensure feedback and support to the specific GP

\subsection{Support \& CPD}

19.1 PWSI and GPwSI will: attend relevant national/international conferences as appropriate

19.2 Pursue involvement in primary care allergy initiatives e.g. guideline development, dissemination of best practice, peer support etc

19.3 Discuss patients and share best practice

19.4 Contribute to clinical and research publications on allergy and related disciplines

19.5 Take advantage of involvement in allergy-related research projects

\subsection{Monitoring \& audit arrangement}

20.1 Bi-monthly reports on attendees, diagnoses, and investigations will be compiled by GPWSI - shared with PCT

20.2 Referral rates to PWSI and GPWSI and effect on referral rates to secondary/tertiary care will be monitored by PWSI and GPWSI and reported to PCT

20.3 Access times to PWSI and GPwSI will be reported weekly to PCT

20.4 A patient satisfaction questionnaire will be outlined by PWSI and GPWSI and collated after 3 months and 6 months

\subsection{Costs}

21.1 Provision for seeing 162 patients over 6 months @ £15000 as previously submitted ie $50 \%$ of budget TOTAL £15,000 
ML Levy et al.

\section{Care Pathway for Allergy PwSI}

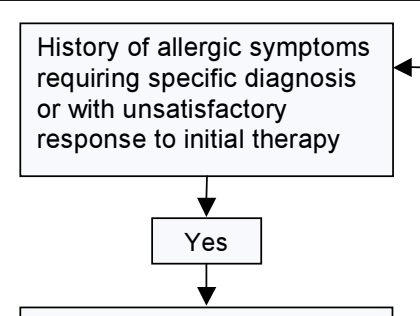

Refer to PwSI Allergy Clinic

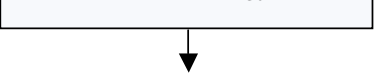

$\infty$ Diagnose/exclude true allergic disease

$\infty$ Specific allergy diagnosis required?

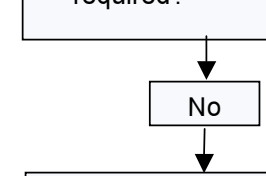

Any unusual features?

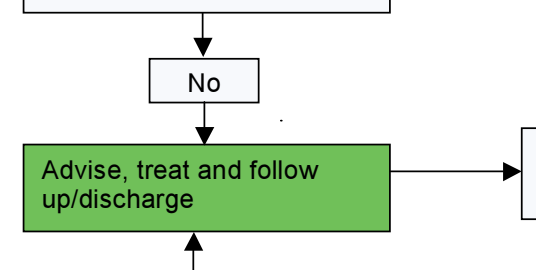

Yes
GP/practice nurse to complete referral form and include with referral letter

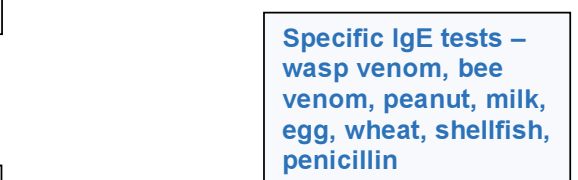
enicillin

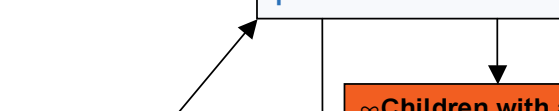

AND confirmed food

allergy

$\infty$ Diagnostic uncertainty

Needing specialist

investigations

$\infty$ Needing specialist

care

Continuing patient

anxiety
Specialist dietician

Allergist/

immunologist

Paediatric

allergist/

dermatologist

ENT consultant

Referring GP 


\section{Appendix 2}

\section{Harrow WTH}

Primary Care Trust

\section{HARROW PCT ALLERGY CLINIC REFERRAL PROFORMA}

$\infty$ Please fill in all relevant data

$\infty$ Please hand to patient with leaflet explaining process

$\infty$ Please give patient Kenton Bridge telephone number and ask them to 'phone for an appointment

$\infty$ Kenton Bridge Telephone No

Fax No

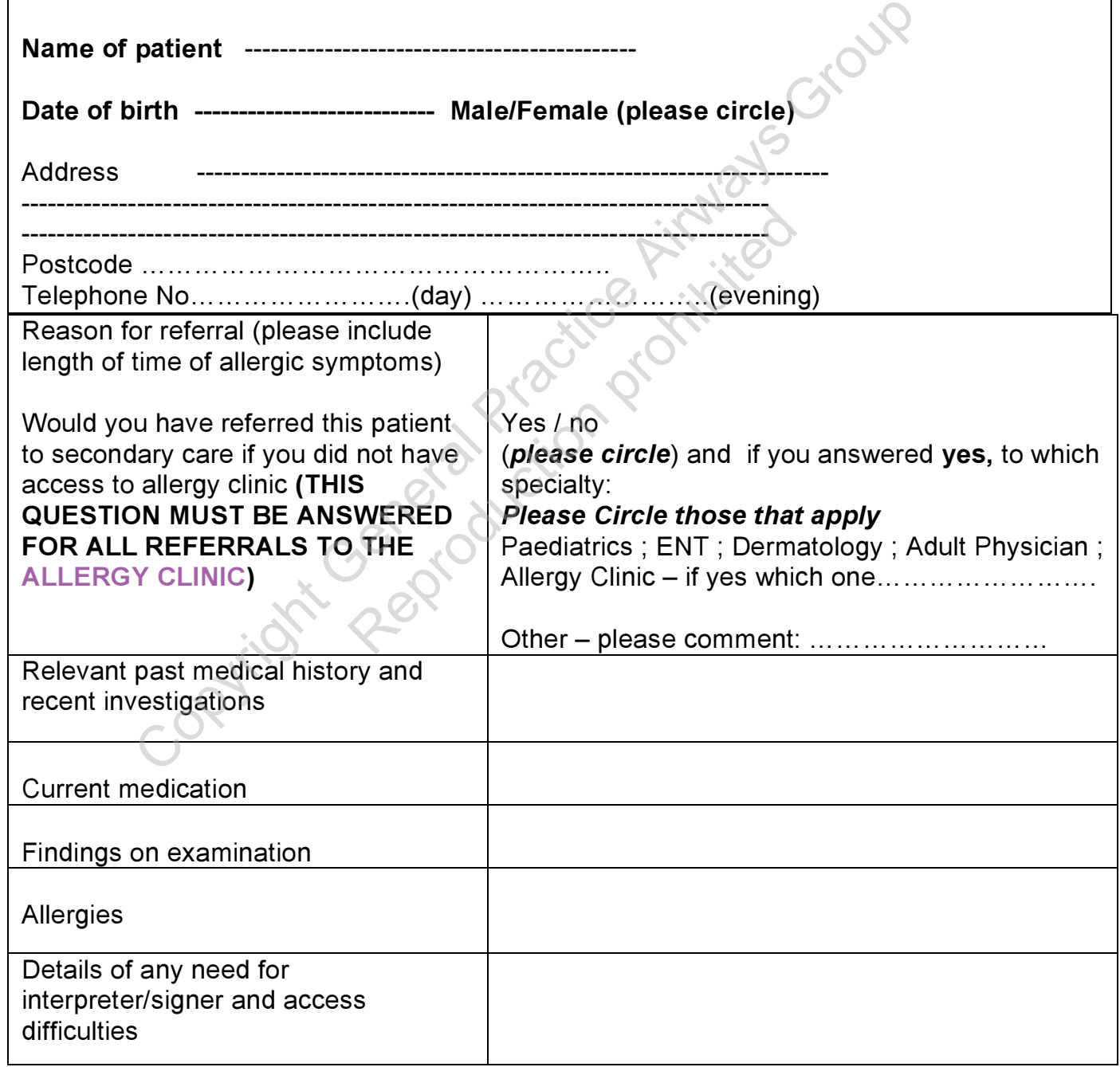

GP signature

PRACTICE STAMP

Date 
$\underline{\text { Guidelines }}$

Conjunctivitis (Owen et al. 2004)

Rhinitis (Bousquet, Van Cauwenberge, \& Khaltaev 2001)

(Sheikh, Dhami, \& Panesar 2003)

Eczema (McHenry, Williams, \& Bingham 2002),

Urticaria (BSACI Guidelines)

Food allergy (Sheikh 2003)

Anaphylaxis (Project Team of The Resuscitation Council (UK) 2001)

\section{References}

Bousquet, J., Van Cauwenberge, P., \& Khaltaev, N. Allergic Rhinitis and its Impact on Asthma. J Allergy Clin Immunol 108(5), s147-s333. 2001.

Ref Type: Journal (Full)

McHenry, P. M., Williams, H. C., \& Bingham, E. A. Management pf atopic eczema. Brit Med J 310, 843-847. 2002.

Ref Type: Journal (Full)

Owen, C. G., Shah, A., Henshaw, K., Smeeth, K., \& Sheikh, A. 2004, "Topical treatments for seasonal allergic conjunctivitis: systematic review and meta-analysis of efficacy and effectiveness", British Journal of General Practice, vol. 54, pp. 451456.

Project Team of The Resuscitation Council (UK). Update on the emergency medical treatment of anaphylactic reactions for first medical responders and for community nurses. Resuscitation 48, 241-243. 2001.

Ref Type: Journal (Full)

Sheikh, A. 2003, "Allergic problems.," in Practical general practice (4th Ed.), A. Khot \& A. Polemar, eds., Butterworth Heneiman, Oxford, pp. 383-387.

Sheikh, A., Dhami, S., \& Panesar, H. S. J. 2003, "Clinical Evidence," S. Barton, ed., BMJ Books, London, pp. 585-597. 


\section{Harrow W/HS \\ Primary Care Trust}

Referral guidance for patients being referred to the PwSI Allergy Clinic (Please complete this form and attach it to referral form

Name of patient

Does the patient fall in to one of the categories listed below? Please tick the appropriate box:

$\infty$ Patients with rhinitis symptoms of sneezing, nasal blockage, rhinorrhoea etc that are unresponsive to combination of nasal steroids and oral antihistamines

$\infty$ Patients who present with acute or chronic hives, or allergic-type wheals or history/signs of suspected allergic facial swelling

$\infty$ Patients with suspected food allergy, particularly those who develop symptoms soon after eating and may have food allergy, but also those with atypical symptoms attributed to food

$\infty$ Patients who have had a suspected anaphylactic episode

$\infty$ Patients with a suspected allergy to penicillin

$\infty$ Patients with systemic reactions (not only local) to a bee, wasp or unknown insect sting
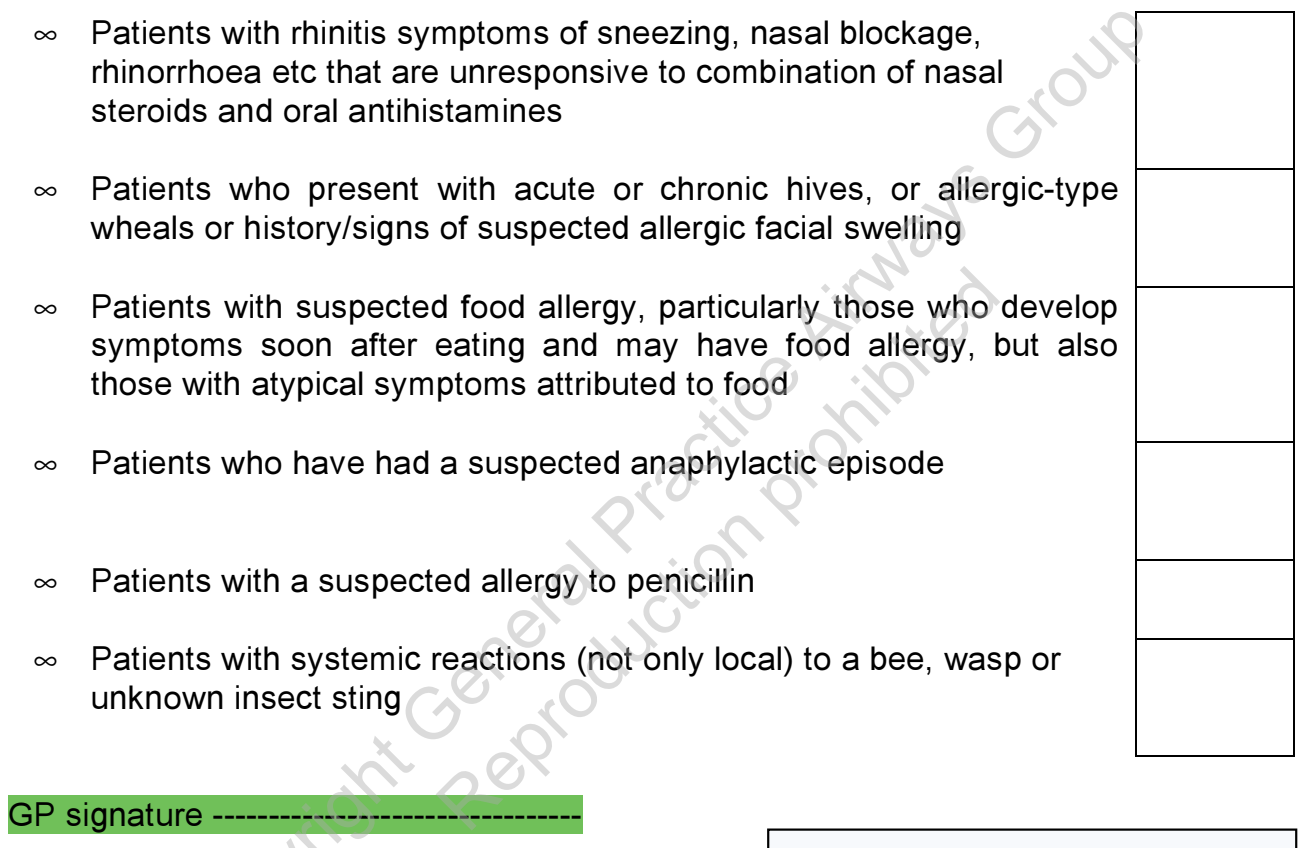

Date $\ldots \ldots \ldots \ldots \ldots \ldots \ldots \ldots$

PRACTICE STAMP 


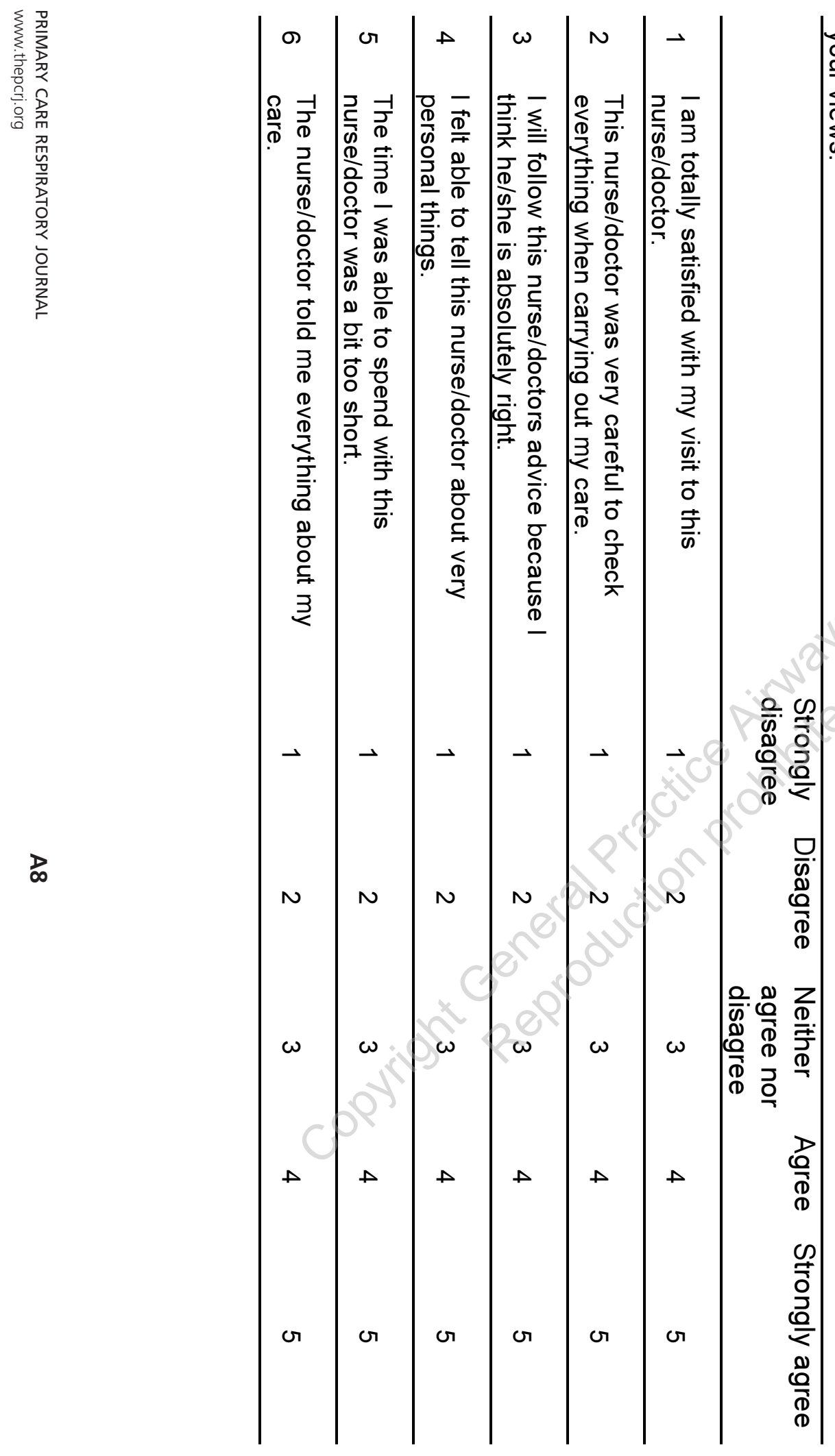

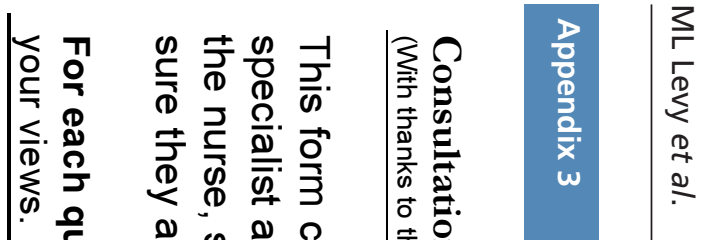
은 ฏ

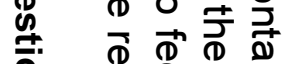

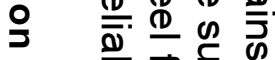

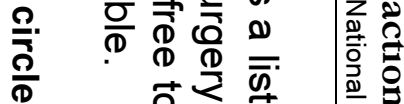

咅 $\quad$ वे

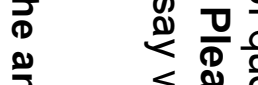

का $\sum \stackrel{0}{0}$

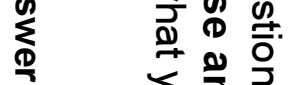

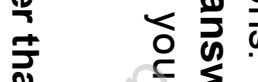

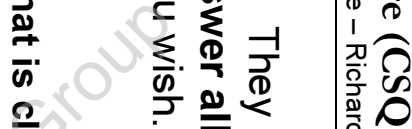

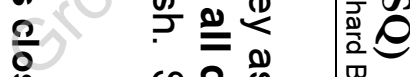

क

ค

ㅇ

睪

노 운

㠃

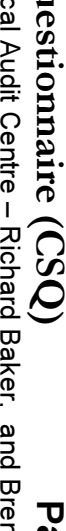

응 文

ำ 응 응

늘

苛 $\stackrel{0}{=}$ 节

б음

줏 के के 줏

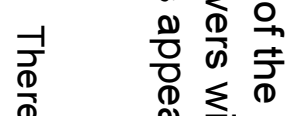

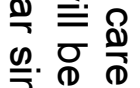

중

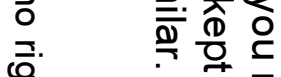

걱 몽

은 $\quad$ क

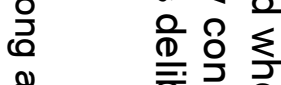

के क्ष

市 焉

() $\underline{0}$

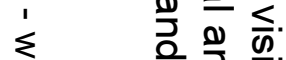

ఏ) क. 这

๗)

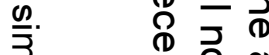

을 $\quad$ की

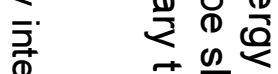

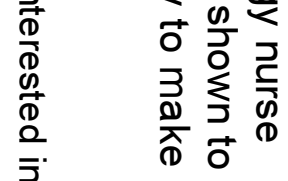

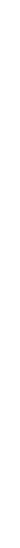

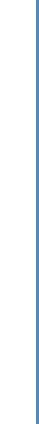




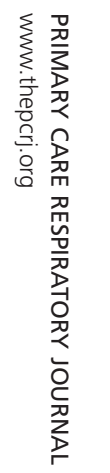

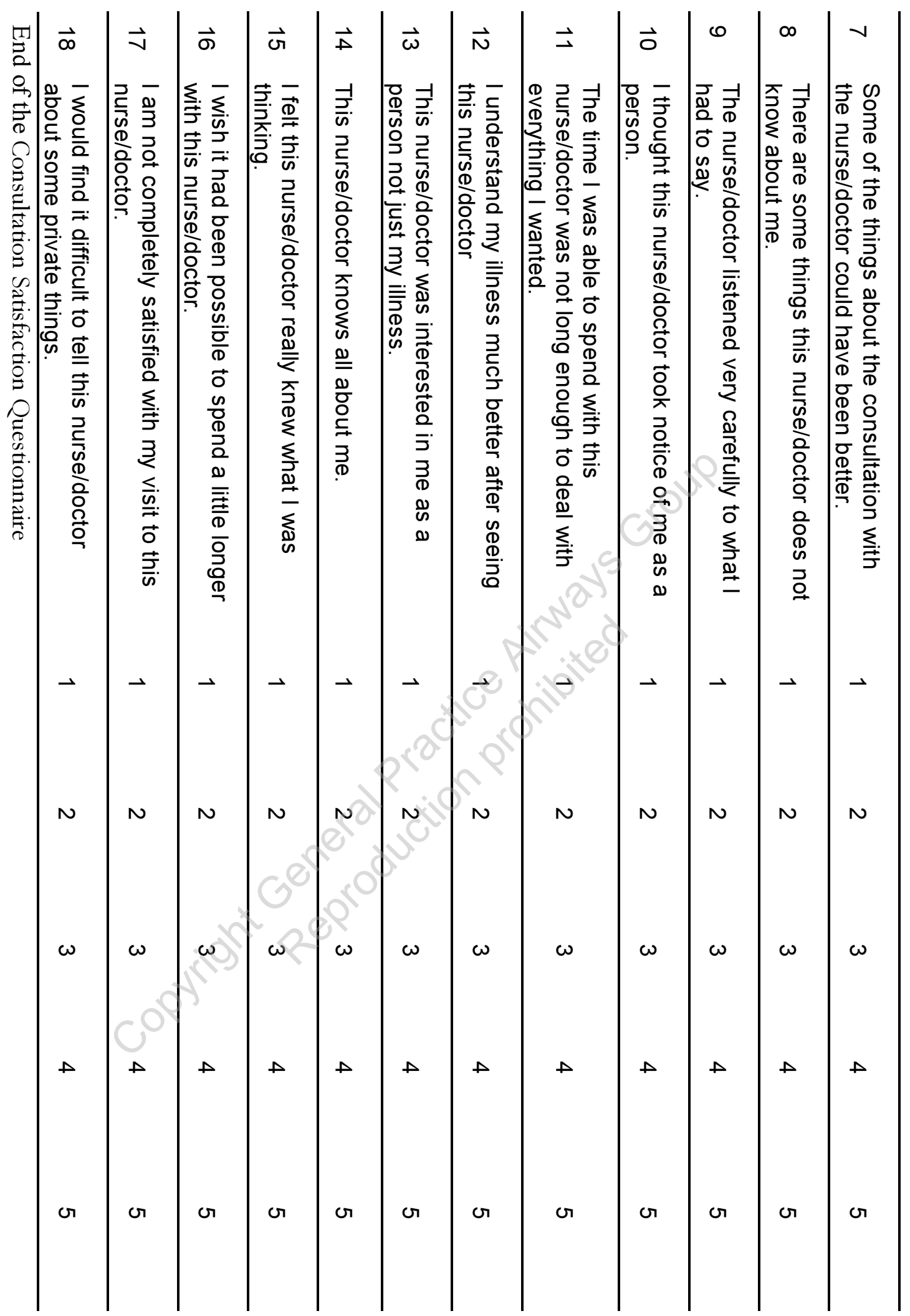

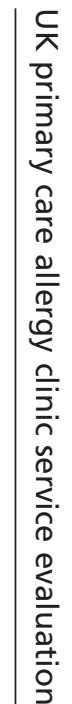

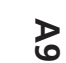




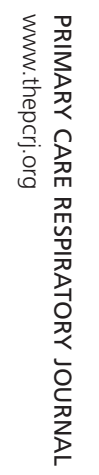

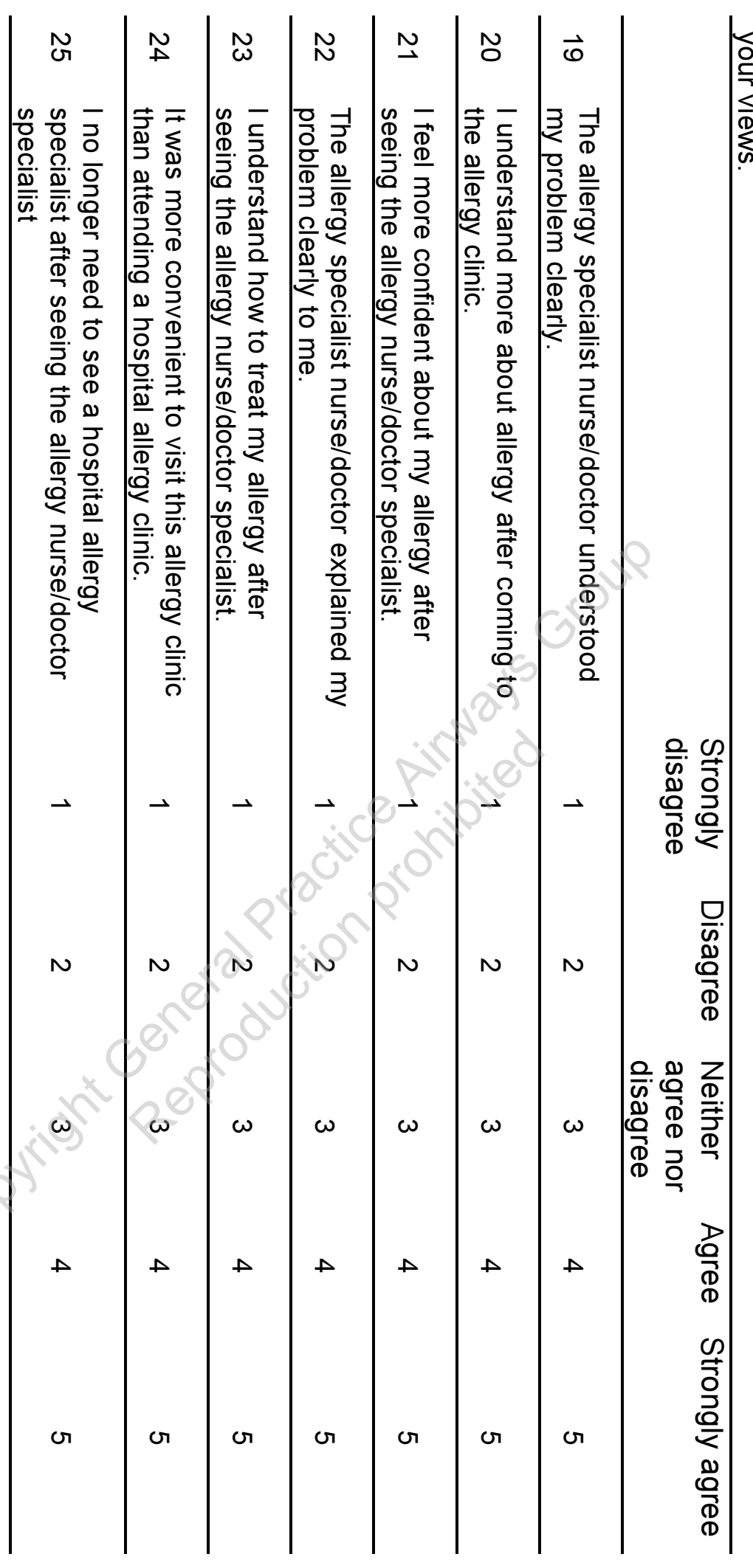

这

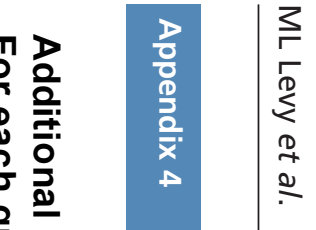

도

․․

음

옥 임

오을

宁 움

옹

노음

음

ธั

옹 웅

号

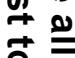

으

$\leq 0$

\#

ํㅡㄹ 긍

$\stackrel{D}{0}$

官.

검

ล)

긍

득

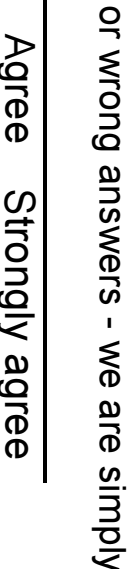

蛋

需

呙 